\title{
Design of Multi-Frequency Ultrasonic Pulse-Echo System
}

\author{
G.K.Singh ${ }^{1}$, S.J.Sharma ${ }^{2}$ and S.Rajagopalan ${ }^{3}$ \\ ${ }^{I}$ Deptt. of Electronics, A.N. College, Anandwan, Warora - 442907 \\ ${ }^{2,3}$ Deptt. of Electronics, RTM Nagpur University, Nagpur- 440033
}

\begin{abstract}
The Pulse-Echo Technique has been evolved to be the most popular, reliable and sustainable amongst all the ultrasonic techniques used to ultrasonic attenuation and velocity measurements for the material characterization. The features of this technique make it an ideal choice for variety of applications as well as hard-core research work. In the present work, A Multi-Frequency Ultrasonic Pulse-Echo System for ultrasonic velocity and attenuation measurements in liquids and liquid mixtures at frequencies from 1 to $10 \mathrm{MHz}$ using offthe- shelf electronic components in our laboratory, is designed. The sample holder, designed in our laboratory, provides variable path length between ultrasonic transducer and reflector and can be adjusted with an accuracy of $\pm 0.01 \mathrm{~mm}$. The designed Multi-Frequency Ultrasonic Pulse-Echo System and the Sample-holder have been tested and found to give reliable result.
\end{abstract}

Keywords: Pulse-Echo Technique, Ultrasonic velocity measurement, Ultrasonic attenuation measurement

\section{Introduction:}

Ultrasonic technique finds wide applications and acceptance in all fields. Ultrasonic attenuation and velocity are the important parameters, which are required for the material characterization. Measurement of attenuation and velocity of ultrasonic waves has been the basis of evaluation of a wide variety of physical properties of gases, liquids, and solids. The ultrasonic attenuation and velocity measurement techniques may be categorized as optical techniques, continuous wave techniques and pulse techniques. The pulse technique is the most widely used technique for making ultrasonic measurements in liquids and solids in the frequency range of a few $\mathrm{KHz}$ to tens of $\mathrm{GHz}$ and in gases in the frequency range of tens of $\mathrm{KHz}$ to a few hundreds of $\mathrm{MHz}$, owing to its high accuracy and reproducibility of the results [1-3]. The Pulse-Echo Technique has evolved to be the most popular, reliable and sustainable technique amongst all the ultrasonic techniques [4]. This technique makes it an ideal choice for variety of applications as well as hard-core research work [5-11].

In the Pulse-Echo Technique, a pulsed rf signal of known frequency is fed to ultrasonic transducer that converts it into a pulsed ultrasonic wave of the same frequency. Ultrasonic pulse travels through the sample and is reflected back from the sample boundaries until it decays away. Each time the ultrasonic pulse strikes the sample end coupled to the transducer, an electrical signal is generated which is amplified and displayed on an oscilloscope. If the pulse duration is small compared to a round-trip transit time in the sample, a pulse-echo decay pattern develops.

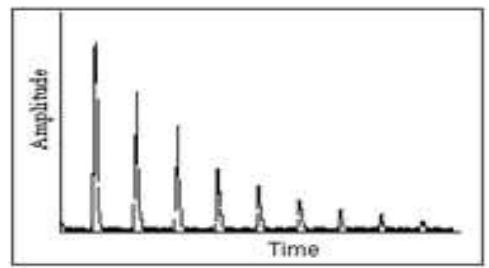

Fig. 1: Typical pulse-echo decay pattern

The amplitudes of echoes formed and displayed on the CRO screen due to passage of short duration pulse through the sample of known path length are measured and the absorption coefficient $(\alpha)$ is determined by fitting this data in the equation:

where,

$$
\alpha=\frac{20}{2 l} \log _{10} \frac{\frac{A_{1}}{A_{2}}+\frac{A_{2}}{A_{3}}+---+\frac{A_{n-1}}{A_{n}}}{n-1} \frac{d B}{c m}
$$

$\alpha:$ attenuation coefficient, $\mathrm{dB} / \mathrm{cm}$

$A_{1}, A_{2}, A_{3},-------, A_{n-1}$, and $A_{n}$ are amplitudes of $n$ echoes, and

$2 l$ : the path length that ultrasonic waves travels in the liquid sample. 
The velocity of ultrasonic wave propagation is determined by measuring the transit time between the reflected pulses and the corresponding pulse propagation distance in the sample.

In the present work, a Multi-Frequency Ultrasonic Pulse-Echo System is designed for attenuation and velocity measurements in liquids. The system is used to measure ultrasonic attenuation and velocity in standard liquids methanol and ethanol at $25{ }^{\circ} \mathrm{C}$ and estimated attenuation and velocity values found to be in agreement with literature value.

\section{Experimental:}

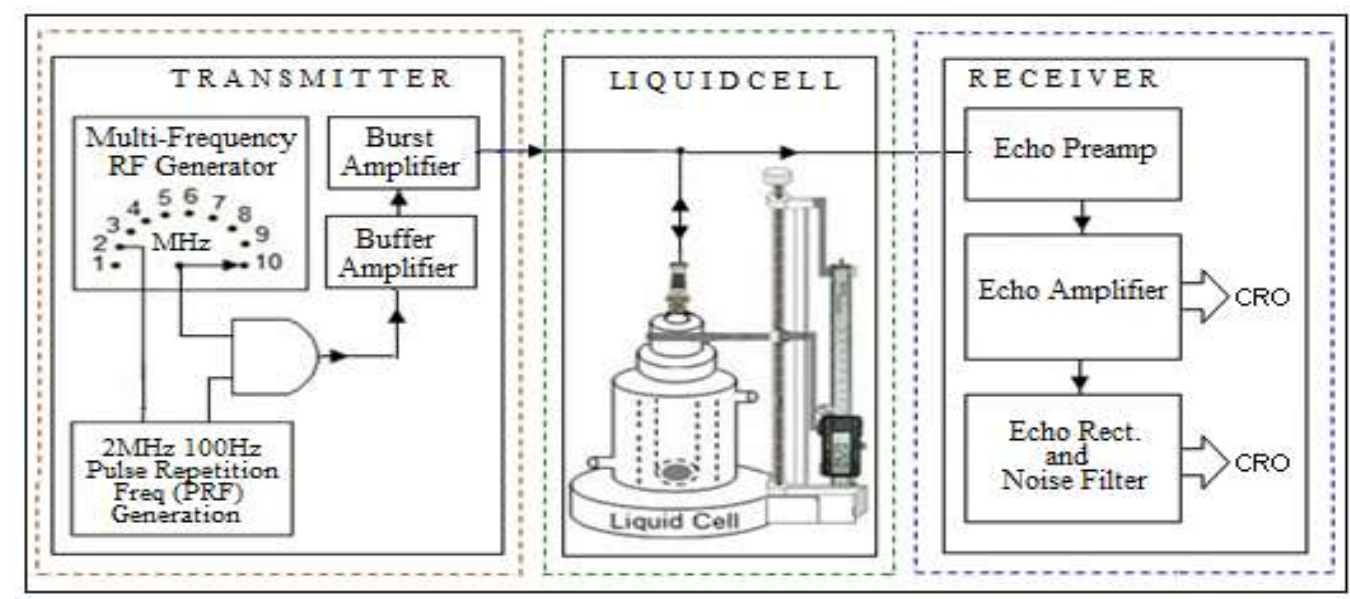

Fig. 2: Block diagram of Multi-Frequency Ultrasonic Pulse-Echo System

\subsection{The Liquid Cell:}

The designed liquid cell, the most important element of ultrasonic measurement system that decides accuracy of the measurement, is shown in Fig. 3. The cell is made up of a double walled stainless steel with a central uniform bore of $43.75 \mathrm{~mm}$ diameter and a depth of 78.08 with a perfectly smooth, highly polished bottom surface. Vertical surface of the cylinder is finely grooved to avoid any reflections of ultrasonic waves. The double walled cylinder is fitted on the base with screws with springs in between cell and base. With fine adjustment of screw, parallelism between the transducer and the reflecting surface can be easily achieved. This is critical during measurements. The cell has an inlet and outlet facility for water circulation in order to keep the sample under study to a constant temperature.

The designed sample holder has provision for attachment of ultrasonic transducers of various frequencies. Piezoelectric transducers of different frequencies (from 1 to10 MHz) fitted with disk holders, can be easily attached to or removed from liquid cell. Thus, the sample holder is effectively used at frequencies from 1 to $10 \mathrm{MHz}$. One of the most important features of this cell is that it provides digital read out of the displacement of ultrasonic transducer with respect to the to the reflecting surface. This is accomplished using a digital vernier calliper firmly fixed to the cell. The displacement between ultrasonic transducer and reflecting surface can be varied with a mechanical knob with an accuracy of $\pm 0.01 \mathrm{~mm}$. This helps in achieving better accuracy in the measurement of ultrasonic attenuation and velocity in differential mode.

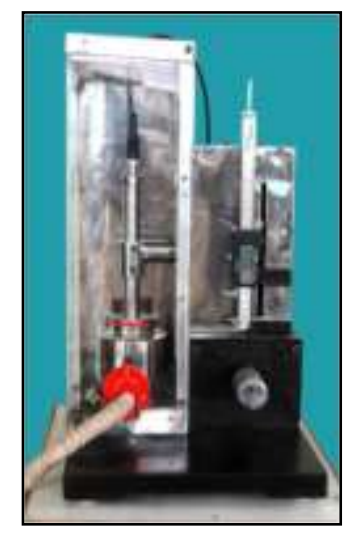

Fig. 3: Sample Holder for Ultrasonic Attenuation and Velocity Measurement in Liquids 


\subsection{Transmitter Module:}

Transmitter module consists of frequency generator, frequency divider, RF burst width controller, gating circuit, and RF burst amplifier and provides a short duration of RF bursts (Fig. 4). These RF burst after amplification (up to 22V) are applied to the ultrasonic transducer to generate ultrasonic waves of known frequency (transducer's natural frequency) that propagate through the liquid in the cell.

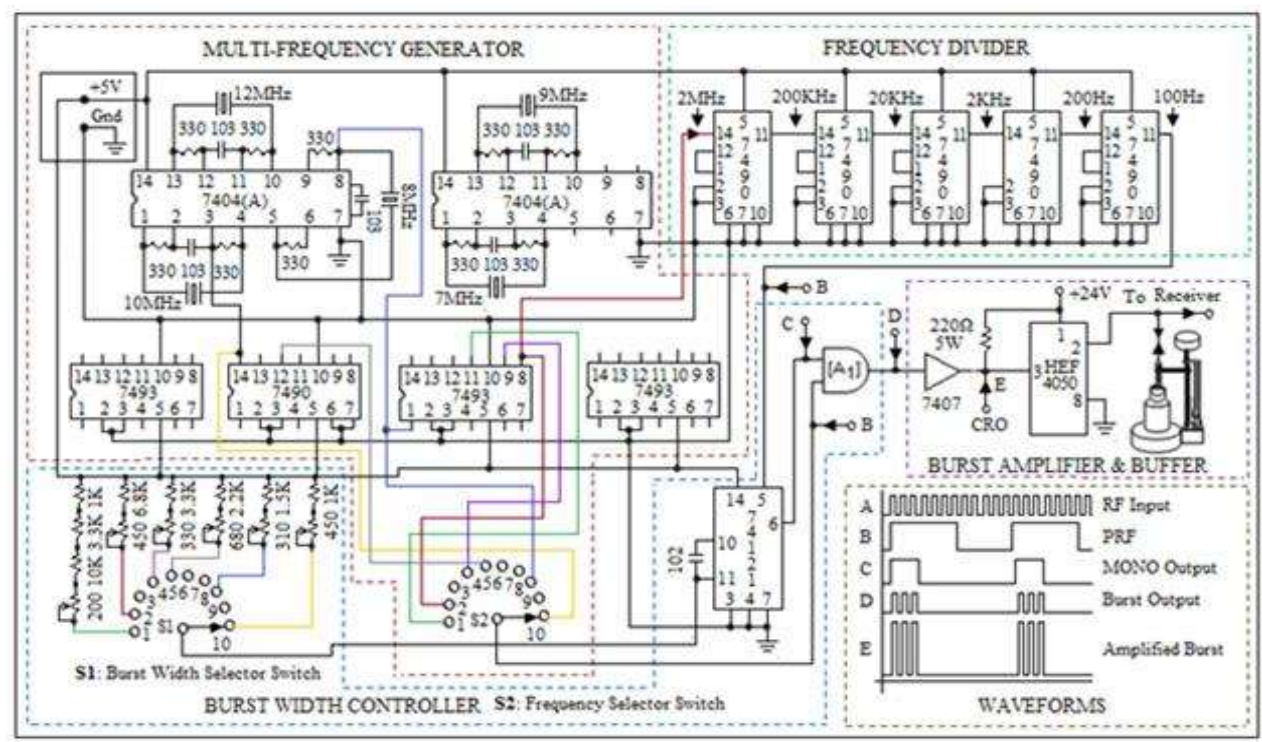

\subsection{Receiver Module:}

Fig. 4: Transmitter Module

The receiver module shown in Fig. 5 consists of echo amplifier, noise filter, and echo rectifier. The two stage amplifiers are designed using ICs AD842 to provide overall gain of $59 \mathrm{~dB}$ [12]. Two fast switching backto-back diodes (1N4148) are connected between inverting input and ground of both amplifiers $\left[\mathrm{A}_{1}\right]$ and $\left[\mathrm{A}_{2}\right]$ to limit the maximum amplitude of signal applied to the input of amplifier and protects it from being damaged from excessive input and noise spike. After amplification, these echoes are fed to the noise filter which consists of $1 \mathrm{~K}$ preset in series with $10 \mathrm{~K}$ resistor connected to $+12 \mathrm{~V}$ dc supply, to set dc potential for the echo rectifier $\left(\mathrm{D}_{7}\right)$ to filter out noises of desired level, and then to echo rectifier circuit designed using fast switching diode $\left(\mathrm{D}_{7}\right)$ to rectify echoes. The output of echo rectifier (point Ao) is connected to CRO where echo pattern as shown in Fig. 1 is displayed. Ehoes amplitudes from CRO screen are found to estimate attenuation coefficient $(\alpha)$ in Neper $\mathrm{m}^{-1} \mathrm{~s}^{2}$ and time of flight between two successive echoes is used to estimate ultrasonic velocity in the sample under study.

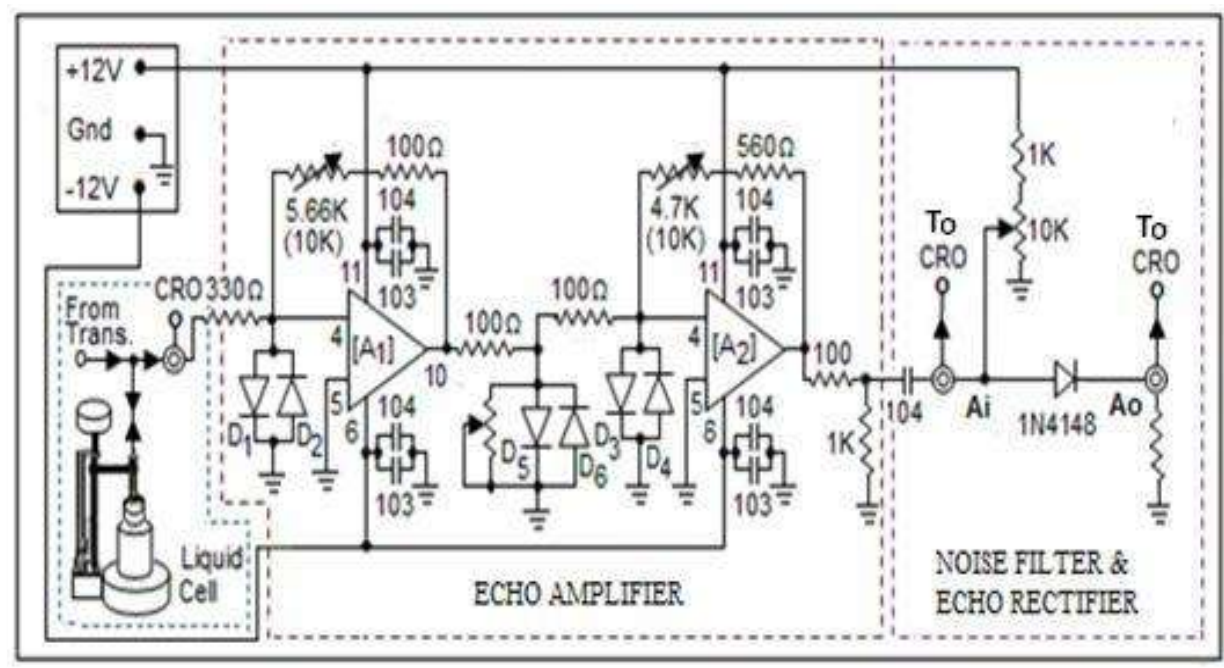

Fig. 5: Receiver Module 
III. Result And Discussion:

Fig. 5 (a\&b) and Fig.6 (a\&b) show screen shots of echoe pattern displayed on oscilloscope for acetone and ethanol at 2 and $5 \mathrm{MHz}$ at $25^{\circ} \mathrm{C}$ for two displacements of ultrasonic transducer from the reflector. Echoes amplitudes and time interval between two echoes are measured and estimation of attenuation and velocity are estimated and are shown in Table 1and Table 2 respectively.
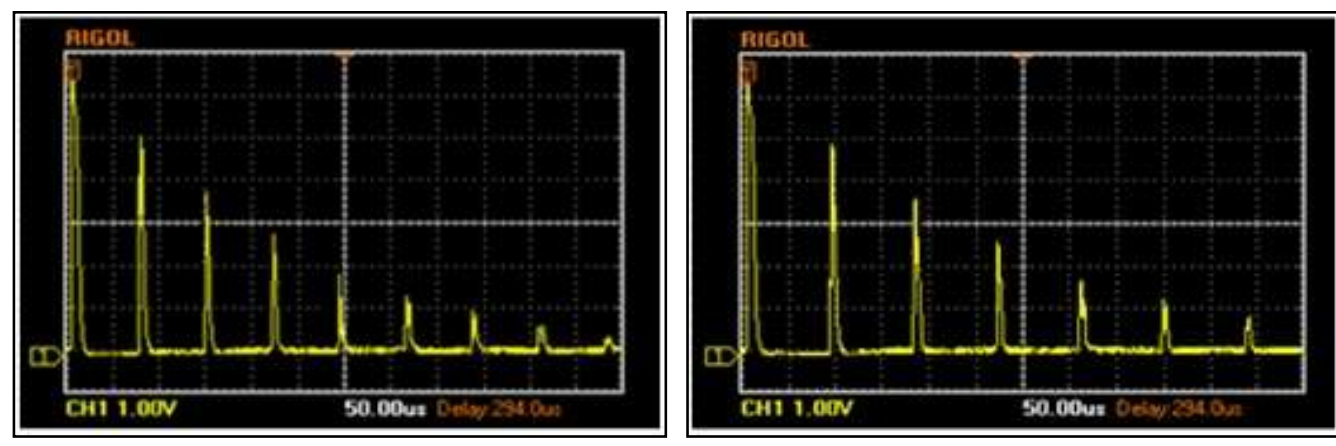

Fig. 5(a): Echo pattern for acetone at $2 \mathrm{MHz}$ for path length of $41.3 \mathrm{~mm}$ and $51.3 \mathrm{~mm}$ respectively
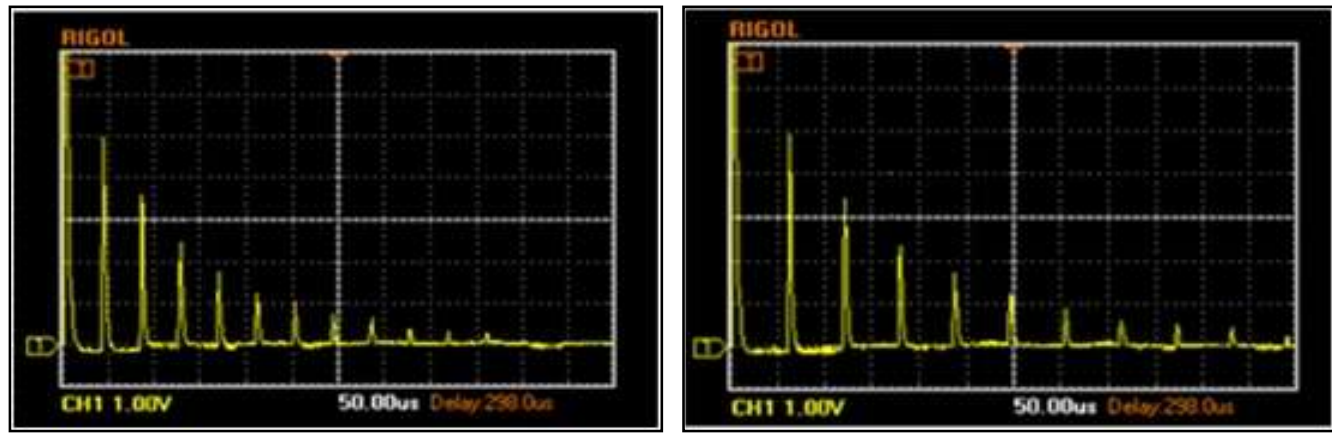

Fig. 5(b): Echo pattern for acetone at 5MHz for path length of $20.0 \mathrm{~mm}$ and $30.0 \mathrm{~mm}$ respectively
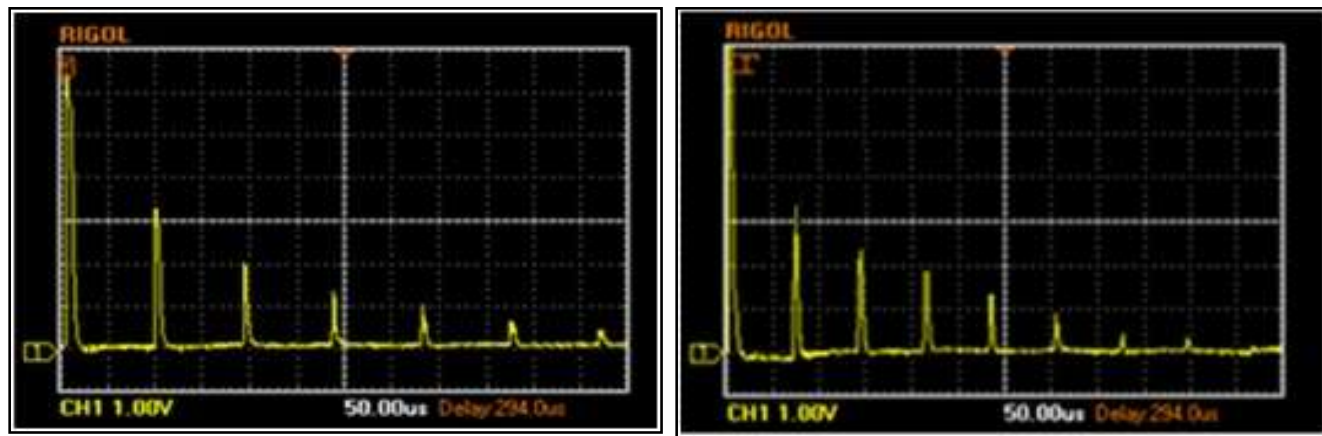

Fig. 6(a): Echo pattern for ethanol at $2 \mathrm{MHz}$ for path length of $41.3 \mathrm{~mm}$ and $51.3 \mathrm{~mm}$ respectively.
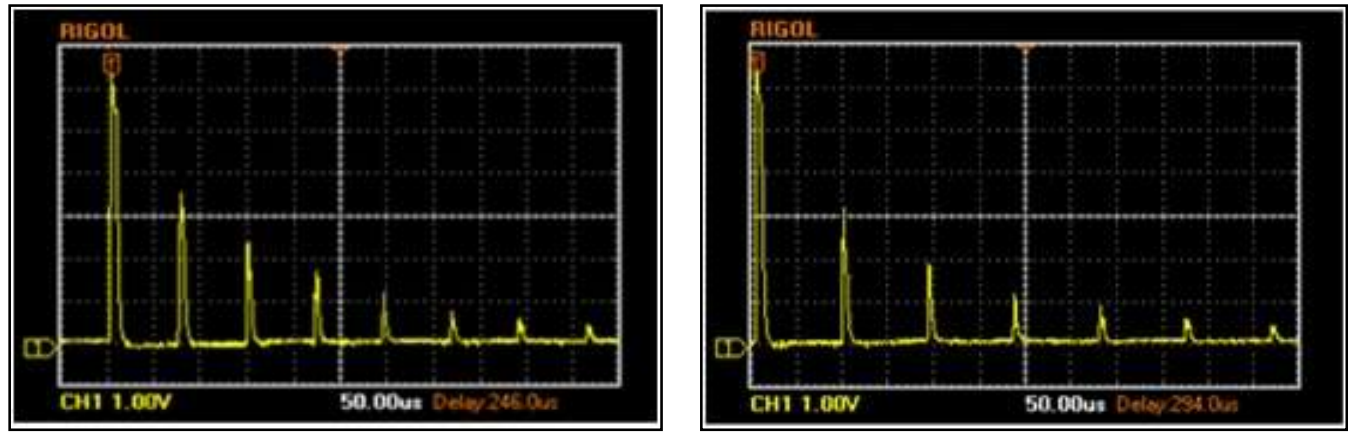

Fig. 6(b): Echo pattern for ethanol at 5MHz for path length of $35.0 \mathrm{~mm}$ and $45.0 \mathrm{~mm}$ respectively. 
Table1: Attenuation and velocity in acetone for 2 and $5 \mathrm{MHz}$ at $25^{\circ} \mathrm{C}$

\begin{tabular}{|c|c|c|c|c|c|c|c|c|c|c|c|c|c|c|}
\hline \multirow{3}{*}{$\begin{array}{c}\text { Freq. } \\
\stackrel{f}{(M H z)}\end{array}$} & \multicolumn{14}{|c|}{ Path length } \\
\hline & \multicolumn{7}{|c|}{$L 1=41.3 \mathrm{~mm}$} & \multicolumn{7}{|c|}{$\mathrm{L} 2=51.3 \mathrm{~mm}$} \\
\hline & $\begin{array}{l}\mathrm{A}_{2} \\
(\mathrm{~V})\end{array}$ & $\left(A_{2}\right)$ & $\begin{array}{l}A_{3} \\
\text { (V) }\end{array}$ & $A_{4}$ & $\begin{array}{l}\mathrm{A}_{s} \\
\text { (V) }\end{array}$ & $\mathrm{A}_{\mathrm{s}}$ & \begin{tabular}{|l|} 
Atten. \\
$\alpha_{L 1}(\mathrm{~dB})$ \\
\end{tabular} & $\begin{array}{c}A_{2} \\
(V)\end{array}$ & $\begin{array}{l}A_{2} \\
(N)\end{array}$ & \begin{tabular}{l|}
$A_{3}$ \\
$(V)$
\end{tabular} & (v) & As, & $\mathrm{A}_{\mathrm{s}}$ & $\begin{array}{l}\text { Atten. } \\
\alpha_{\mathrm{L}}(\mathrm{dB})\end{array}$ \\
\hline \multirow[t]{2}{*}{2} & 4.999 & 3.747 & 2.723 & 1.850 & 1.343 & 0.009 & 3.009 & 4.999 & 3.687 & 2.677 & 1.670 & 1.127 & 0.766 & 3.0458 \\
\hline & \multicolumn{7}{|c|}{$\mathrm{L} 1=20.0 \mathrm{~mm}$} & \multicolumn{7}{|c|}{$\mathrm{L} 2=30.0 \mathrm{~mm}$} \\
\hline 5 & 4.899 & 3.547 & 2.577 & 1.751 & 1.270 & 1.007 & 2.7471 & 4.999 & 3.471 & 2.390 & 1.703 & 1.296 & 0.888 & 2.9844 \\
\hline
\end{tabular}

\begin{tabular}{|c|c|c|c|c|c|c|c|c|}
\hline \multicolumn{4}{|c|}{ Attenuation } & \multicolumn{5}{|c|}{ Velocity } \\
\hline \multicolumn{3}{|c|}{ Path Diff. $\triangle \mathrm{L}=10 \mathrm{~mm}$} & & Time & of fligh & (us) & & \\
\hline $\begin{array}{l}\text { Atten } \\
\Delta \alpha(\mathrm{dB})\end{array}$ & $\alpha$ Atten. & $\begin{array}{c}\text { Atten. } \\
\alpha / \mathrm{f}^{2}\left(\mathrm{Npm}^{-2} \mathrm{~s}^{2}\right)\end{array}$ & \begin{tabular}{|l|} 
Lit.Value \\
(Npm $\left.{ }^{-2} S^{2}\right)$
\end{tabular} & T1 & T2 & $\Delta \mathrm{T}$ & $(\mathrm{m} / \mathrm{s})$ & $\begin{array}{l}\text { Lir. Value } \\
\text { (m/s) }\end{array}$ \\
\hline 0.0368 & 0.0184 & $5.2959 \times 10^{37}$ & \multirow{3}{*}{$\begin{array}{c}35 \\
{[13]}\end{array}$} & 72.20 & 89.25 & 17.05 & 1173.021 & \multirow{3}{*}{$1170.000[13]$} \\
\hline \multicolumn{3}{|c|}{ Path Diff. $\Delta L=10 \mathrm{~mm}$} & & \multicolumn{4}{|c|}{ Path Diff. $\Delta L=10 \mathrm{~mm}$} & \\
\hline 0.1373 & 0.0687 & $3.1637 \times 10^{24}$ & & 42.00 & 59.05 & 17.05 & 1173.021 & \\
\hline
\end{tabular}

Table 2: Attenuation and velocity in ethanol for 2 and $5 \mathrm{MHz}$ at $25^{\circ} \mathrm{C}$

\begin{tabular}{|c|c|c|c|c|c|c|c|c|c|c|c|c|c|c|}
\hline Freq. & \multicolumn{14}{|c|}{ Path length } \\
\hline \multirow[b]{2}{*}{$\stackrel{f}{f} \stackrel{(M \mathrm{~Hz})}{ }$} & \multicolumn{7}{|c|}{$\mathrm{L} 1=41.3 \mathrm{~mm}$} & \multicolumn{7}{|c|}{$\mathrm{L} 2=51.3 \mathrm{~mm}$} \\
\hline & $\begin{array}{c}\mathrm{A}_{1} \\
\text { (V) }\end{array}$ & $\begin{array}{l}A_{2} \\
\text { (V) }\end{array}$ & \begin{tabular}{|c|}
$A_{3}$ \\
(V)
\end{tabular} & $\begin{array}{l}\mathrm{A}_{4} \\
\text { (V) }\end{array}$ & \begin{tabular}{|l}
$A_{s}$ \\
(V)
\end{tabular} & $\begin{array}{c}A_{5} \\
\text { (v) }\end{array}$ & \begin{tabular}{|c|} 
Atten: \\
$\alpha_{\perp 1}$ (dB) \\
\end{tabular} & $\begin{array}{c}\mathrm{A}_{2} \\
\text { (V) }\end{array}$ & $\begin{array}{l}\mathrm{A}_{2} \\
\text { (V) }\end{array}$ & $\begin{array}{l}\mathrm{A}_{3} \\
(\mathrm{~V})\end{array}$ & $\begin{array}{l}A_{4} \\
\text { (V) }\end{array}$ & $\begin{array}{l}\mathrm{As}_{3} \\
\text { (V) }\end{array}$ & $\begin{array}{l}\mathrm{A}_{5} \\
\text { (V) }\end{array}$ & $\begin{array}{l}\text { Atten. } \\
\alpha_{-2}(\mathrm{~dB})\end{array}$ \\
\hline \multirow[t]{2}{*}{2} & 3.565 & 2.474 & 1.702 & 1.145 & 0.776 & 0.541 & 3.2752 & 3.141 & 2.083 & 1.432 & 1.022 & 0.688 & 0.466 & 3.3168 \\
\hline & \multicolumn{7}{|c|}{$\mathrm{L} 1=35.0 \mathrm{~mm}$} & \multicolumn{7}{|c|}{$\mathrm{L} 2=45.0 \mathrm{~mm}$} \\
\hline 5 & 3.165 & 2.258 & 1.956 & 1.316 & 0.739 & 0.384 & 3.8010 & 3.022 & 1.888 & 1.173 & 0.781 & 0.461 & 0.298 & 4.0279 \\
\hline
\end{tabular}

\begin{tabular}{|c|c|c|c|c|c|c|c|c|}
\hline \multicolumn{4}{|c|}{ Attenuation } & \multicolumn{5}{|c|}{ Velocity } \\
\hline \multicolumn{3}{|c|}{ Path Diff. $\Delta L=10 \mathrm{~mm}$} & \multirow[b]{2}{*}{$\begin{array}{l}\text { Lit.Value } \\
\left.\text { (Npm }{ }^{-2} \mathrm{~s}^{2}\right)\end{array}$} & \multicolumn{3}{|c|}{ Time of flight (us) } & \multirow{2}{*}{$\underset{(\mathrm{m} / \mathrm{s})}{\mathrm{u}}$} & \multirow{2}{*}{$\begin{array}{l}\text { Lit. Value } \\
(\mathrm{m} / \mathrm{s})\end{array}$} \\
\hline $\begin{array}{l}\text { Atten } \\
\Delta \alpha(\mathrm{dB})\end{array}$ & $\alpha \begin{array}{c}\text { Atten. } \\
\alpha(\mathrm{dB} / \mathrm{cm})\end{array}$ & $\begin{array}{c}\text { Atten. } \\
\alpha / \mathrm{f}^{2}\left(\mathrm{Npm}^{-2} \mathrm{~s}^{2}\right)\end{array}$ & & T1 & $\mathrm{T} 2$ & $\Delta \mathrm{T}$ & & \\
\hline 0.0416 & 0.0208 & $5.9866 \times 10^{24}$ & \multirow{3}{*}{$\begin{array}{c}51 \\
{[13]}\end{array}$} & 73.10 & 89.95 & 16.85 & 1186.944 & \multirow{3}{*}{$\begin{array}{l}1143.100[14] \\
1207.000[15]\end{array}$} \\
\hline \multicolumn{3}{|c|}{ Path Diff. $\Delta L=10 \mathrm{~mm}$} & & \multicolumn{4}{|c|}{ Path Diff. $\Delta \mathrm{L}=10 \mathrm{~mm}$} & \\
\hline 0.2269 & 0.1135 & $5.2268 \times 10^{24}$ & & 68.75 & 88.95 & 17.20 & 1162.791 & \\
\hline
\end{tabular}

IV.

Conclusion:

In the present work, Multi-Frequency Ultrasonic Pulse-Echo system is designed in our laboratory. The facility of designed system is used to estimate the ultrasonic attenuation and velocity in acetone and ethanol at $25{ }^{0} \mathrm{C}$ temperature. The designed system is found to work satisfactorily and the results agree with literature value.

\section{Acknowledgement:}

One of the authors is grateful to Dr. V. D. Bhandakkar, Head, Deptt. of Electronics, A.N.College, Warora, for full cooperation during this work. The author is also thankful to Dr. Milind Despande, Head, Deptt. of Physics, A. N. College, Warora, for his keen interest in present work.

\section{References:}

[1] Jugan J., Ultrasonic absorption and Acoustic Non-Linearity Parameter B/A of Binary Liquid Mixtures, Thesis, Mahatma Gandhi University, Kottayam-686560 (2002)

[2] Pellam J. R. and Galt J. K., Ultrasonic Propagation in Liquids: I. Application of Pulse Technique to Velocity and Absorption Measurements at 15 Megacycles, J. Chem. Phys., 14(10), 608-614 (1946)

[3] Pinkerton J. M. M., A Pulse Method for the Measurement of Ultrasonic Absorption in Liquids: Results for Water, Nature, 160(4056), 128-129 (1947)

[4] Papadakis E. P., Ultrasonic Phase Velocity by the Pulse-Echo-Overlap Method Incorporating Diffraction Phase Corrections, J. Acoust. Soc. Am., 42( 5), 1045-1051 (1967)

[5] Blitz J., Fundamentals of Ultrasonics, Butterworths, London (1963)

[6] Vigoureux P., Ultrasonics, Chapman \& Hall Ltd., London (1952)

[7] Sharma S.J., Ultrasonic Propagation Studies in Polymers, Ph.D. Thesis, Nagpur University, Nagpur (1998)

[8] Certo M., Dotti D. and Vidali P., A programmable pulse generator for piezoelectric multielement transducers, Ultrasonics., 22(4), 163-166 (1984)

[9] Froelich B., A simple apparatus for automatic pulse echo tracking Apparatus and Techniques, J. Phys. E: Sci. Instrum., 10 (3), 210 (1976)

[10] Vyaghra V. R, Sharma S. J. and Rajagopalan S., PC based high resolution velocity measurement in pulse echo setup, International Conference on Instrumentation (INCON 2004), 74, Pune, India

[11] Dubey P. K., Rajagopalan S., Vyaghra V. R., Pendsey V. M. and Sharma S. J., High resolution Ultrasonic Attenuation Measurement in Pulse-echo Setup, MAPAN - J. of metrology Society of India, 23( 4), 245-252 (2008)

[12] AD-842 (Wideband, High Output Current, Fast Settling Op Amp), www.analog.com

[13] The speed and attenuation of sound, www.kayelaby.npl.co.uk

[14] Resa J.M., Gonzalez C., Goenaga J.M. and Iglesias M., Influence of temperature on ultrasonic velocity measurements of Ethanol+Water+1-Propanol Mixtures, J. Therm. Anal. Cal., 87(1), 237-245 (2007)

[15] Gandole Y. B., Development of Signal Processing Techniques for Ultrasonic Measurements, Indian. J. Sci. Technol., 4(10) (2011) 